\title{
Simple epidemiology model for a non-immune disease with ordinary and resistant carriers
}

\author{
Ilnytskyi H. ${ }^{1}$, Ilnytskyi J. ${ }^{2,3}$ \\ ${ }^{1}$ Danylo Halytskyi Lviv National Medical University \\ 69 Pekarska Str., 79000, Lviv, Ukraine \\ ${ }^{2}$ Institute for Condensed Matter Physics of the Nat. Acad. Sci. of Ukraine \\ 1 Svientsitskii Str., 79011 Lviv, Ukraine \\ ${ }^{3}$ Lviv Polytechnic National University \\ 12 S. Bandera str., 79013, Lviv, Ukraine
}

(Received 29 June 2017)

\begin{abstract}
We consider the compartmental model for the non-immune disease with both ordinary and resistant carriers. The same infecting rate $\beta$ is assumed for both types of carriers, whereas the curing rates $\gamma$ and $\gamma^{\prime}$ for the ordinary and resistant carriers, respectively, are different. The conversion from an ordinary into resistant carrier takes place with the rate $\delta$. The stationary states for the model are evaluated and rewritten in a compact form using two reduced parameters that are combinations of initial four rates. The lower and upper bounds are given for both these parameters and the $3 D$ plot for the fixed points is presented.
\end{abstract}

Keywords: epidemiology, resistant carriers.

2000 MSC: 92C60, 92D 30

UDC: 004.942:[616.9-022-021484:616-036.22]

\section{Motivation and formulation of the model}

Resistance of the diseases to antibiotics treatment poses a serious problem in terms of the increase of mortality and prolongation of hospital stay $[1,2]$. As the result, instead of the first-line antibiotics one is forced to use more expensive second- or third-line ones and intensify the search and clinical tests for the new, previously unused, medicals. The annual cost associated with antibiotic-resistant infections is estimated to reach about 1.5 billion euros in Europe and about 16 billion US dollars in USA [3] and continue to grow. The problem also is a serious thread in Ukraine, according to a recent survey data [4].

The principal mechanism for developing drug resistance is by conversion of the ordinary (nonresistant) carrier into a resistant one. This occurs as the result of incorrect, irregular or incomplete treatment, or as a consequence of a weak immunity of infected host. After this stage, both strains coexist and compete one with another within the body with various outcome scenarious (coexistence on even levels or suppression of one of the strains by another). Active strains of both types are able to spread theirselves independently to healthy individuals by means of a relevant mechanism (e.g. physical contact, coughing, etc.). This scenario has some dangerous caveats in it. For instance, the resistant carrier could already exist in the patient's body before receiving a treatment but is suppressed by the overwhelming numbers of an ordinary carrier. The treatment, targeted at the ordinary carriers, removes these and the resistant strain faces no more competition, overtaking, as the result, the body of a patient. In this way, the treatment leads to quite an opposite effect than desired: the patient at the end is infected by a more severe strain.

J.M.I. acknowledges inspiring discussions with H.Katriel and financial support via FP7 EU IRSES project No. 612669 "Structure and Evolution of Complex Systems with Applications in Physics and Life Sciences" 
Mathematical modelling of the spread of such diseases is a vital component of a general agenta of lowering down the epidemiologic danger they pose. A range of model has been suggested recently that address this problem in a various ways [5-8]. According to the mechanism of conversion of the ordinary carrier into a resistant one, outlined above, it is quite clear that both intra- and inter-host processes should be properly accounted for when modelling the spread of such disease. A comprehensive classification of available models for the intra-host coexistence of carriers is given by Spicknall et al. [9]. In the even level coexistence models the strains cannot convert from one type to another of replace each other, hence they do not compete. Two cases are possible here: (a) single strain infection or (b) superinfection, where the host is infected by both strains simultaneously. In the models with no coexistence no conversion is allowed and the strains compete one with another. Two cases are possible here: (c) exclusive infection (if no replacement is allowed) or (d) replacement infection. Finally, the models with uneven level coexistence allow conversion of strains but no their replacement and present the case of a coexistence in a form of majority/minority. Two cases are possible here: (e) unidirectional conversion, e.g. ordinary into resistant strain conversion is possible only and (f) bidirectional conversion (both ways conversion is possible). The inter-host infecting is similar to the one for the ordinary carrier disease only, but takes place for two strains independently. Therefore, a wide class of models exist and a choice is based on a particular disease and on the desired level of complexity of the epidemiological study [10].
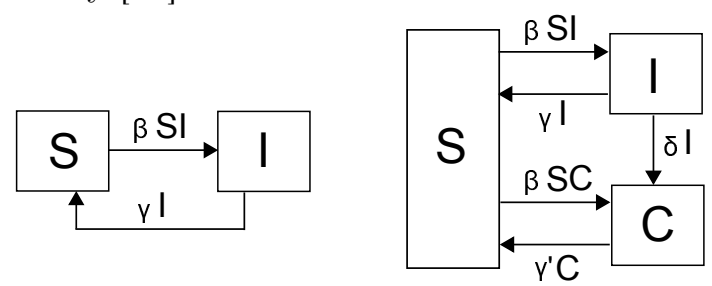

Fig. 1. Flow charts for the SIS (left frame) and $S I C S$ (right frame) epidemiology models.
The aim of our study is to consider a simple epidemiology model termed hereafter as the SICS model, which mimics some principal features of the disease with ordinary and resistant carriers and is suited for both analytic and computer simulation [11-14] studies. To this end we start fom the fixed population SIS model shown in the left frame of Fig. 1 which contains two compartments: $S$ of susceptable individuals, and $I$ of infected ones. Infecting and curing rates are denoted as $\beta$ and $\gamma$, respectively.

It is generalised by adding the third compartment, $C$, of individuals infected with resistant strain and by adding new transitions rules $S \rightarrow C, C \rightarrow S$ and $I \rightarrow C$. In the simplest case one can assume that infecting rate does not depend on the type of a strain but on a level of mixing of individuals, therefore we set the same infecting rate $\beta$ for both $S \rightarrow I$ and $S \rightarrow C$ events. The unidirectional conversion $I \rightarrow C$ takes place with the rate $\delta$, whereas no reverse conversion is possible. Finally, the individuals from the $C$ compartment are cured with the rate $\gamma^{\prime}$ which is different from that from the $I$ compartment, $\gamma$. This mimics the real therapeutic situation when the patient infected with resistant strain is cured by the second- or third-line antibiotics with different curing effectiveness. In Sec. 2 we analyse the stationary solutions of the set of differential equations for the SICS model.

\section{Stationary solutions of the SICS model}

Let us start by brief recalling the stationary solutions for the SIS model. The flow chart for this model, shown in the left frame of Fig. 1, yields the following set of differential equations:

$$
\begin{gathered}
\left\{\begin{array}{c}
\dot{S}=-\beta S I+\gamma I \\
\dot{I}=\beta S I-\gamma I,
\end{array}\right. \\
S+I=1 .
\end{gathered}
$$

where $S$ is the fraction of susceptable individuals and $I$ is the fraction of infected ones. Stationary states are characterised by the fixed point condition $\dot{S}=0$ and $\dot{I}=0$, which, as follows from Eqs. (1), results in a single equation:

$$
-\beta S^{*} I^{*}+\gamma I^{*}=0
$$


where hereafter the asterisk indicates the value of the property in a fixed point. There are two fixed points in total:

- a trivial, disease-free fixed point:

$$
S^{*}=1, \quad I^{*}=0 \text { and }
$$

- a non-trivial fixed point:

$$
S^{*}=\frac{\gamma}{\beta}, I^{*}=1-\frac{\gamma}{\beta} .
$$

The latter is found from Eq. (3) by using the condition (2). One should note that both $S^{*}$ and $I^{*}$ here depend exclusively on the ratio $\gamma / \beta$ between curing and infecting rates, its reciprocal provides the reproduction ratio $R=\beta / \gamma$ of the infection.

We will switch now to the constant population SICS model. Its flow chart, shown in the right frame of Fig. 1, yields the following set of differential equations:

$$
\begin{aligned}
& \left\{\begin{aligned}
\dot{S} & =-\beta S I-\beta S C+\gamma I+\gamma^{\prime} C \\
\dot{I} & =\beta S I-\gamma I-\delta I \\
\dot{C} & =\beta S C-\gamma^{\prime} C+\delta I \\
S & +I+C=1
\end{aligned}\right.
\end{aligned}
$$

where $C$ is the fraction of individuals infected by a resistant strain.

The conditions for the stationary state for the SICS model: $\dot{S}=0, \dot{I}=0$ and $\dot{S}=0$ yields:

$$
\left\{\begin{array}{l}
-\beta S^{*} I^{*}-\beta S^{*} C^{*}+\gamma I^{*}+\gamma^{\prime} C^{*}=0, \\
\beta S^{*} I^{*}-\gamma I^{*}-\delta I^{*}=0, \\
\beta S^{*} C^{*}-\gamma^{\prime} C^{*}+\delta I^{*}=0 .
\end{array}\right.
$$

Asuming $\delta>0$, there are three fixed points in total:

- a trivial, disease-free, fixed point:

$$
S^{*}=1, \quad I^{*}=0, \quad C^{*}=0,
$$

- full conversion fixed point: $I^{*}=0, C^{*}>0$ :

$$
S^{*}=\frac{\gamma^{\prime}}{\beta}, \quad I^{*}=0, \quad C^{*}=1-\frac{\gamma^{\prime}}{\beta}, \quad \text { and }
$$

- a non-trivial fixed point: $I^{*}>0, C^{*}>0$.

The latter case is solved using the following calculations. Assuming $I^{*}>0$, one obtains $S^{*}=$ $(\gamma+\delta) / \beta$ straightaway from the second equation of Eqs. (8). It is substituted then into the first equation of Eqs. (8) yielding the equation containing $I^{*}$ and $C^{*}:-(\gamma+\delta)\left(I^{*}+C^{*}\right)+\gamma I^{*}+\gamma^{\prime} C^{*}=0$. Using condition (7) and grouping terms by powers of $\delta$ one obtains the following solution for the case of a non-trivial fixed point:

$$
\left\{\begin{array}{l}
S^{*}=\frac{\gamma}{\beta}+\frac{1}{\beta} \delta \\
I^{*}=1-\frac{\gamma}{\beta}-\left[\frac{1-\frac{\gamma}{\beta}}{\gamma^{\prime}-\gamma}+\frac{1}{\beta}\right] \delta+\frac{1}{\beta\left(\gamma^{\prime}-\gamma\right)} \delta^{2}, \\
C^{*}=\frac{1-\frac{\gamma}{\beta}}{\gamma^{\prime}-\gamma} \delta-\frac{1}{\beta\left(\gamma^{\prime}-\gamma\right)} \delta^{2},
\end{array}\right.
$$


One can made following observation based on the solutions (9)-(11). Omitting a trivial solution (9), one can proceed straight to the full conversion one, Eq. (10). It is the same as the non-trivial solution for the SIS model (Eq. (5), but with all individuals infected by an ordinary carrier being converted into the ones infected by resistant strain and $\gamma$ replaced by $\gamma^{\prime}$. This stationary state of the $S I C S$ model is, therefore, reduced to that of the SCS one (the SICS model with $I=0$ ). Proceeding further to the solution (11), one should note that there is no $S I S$ model limit $C^{*}=0, I^{*}>0$ at a nonzero conversion rate $\delta>0$. This is evident from the third equation of Eqs. (8) and it is also quite clear straight from the flow diagram for the SICS model in Fig. 1. Indeed, $C^{*}=0$ requires that there is no flow from the $I$ compartment which is possible either at $I^{*}=0$ or at $\delta=0$. In both cases the system will be found in the trivial fixed point (9), as far as no individuals will be found in the $C$ compartment from the very beginning. Therefore, one can never zero fraction $C^{*}$ in a stationary state of the SICS model at a non-zero conversion rate $\delta$.

One of clinically useful characteristics is the relative fraction $f^{*}$ of individuals infected by resistant carrier with respect to the total number of infected individuals. In the stationary state characterised by a non-trivial fixed point one obtains:

$$
f^{*}=\frac{C^{*}}{I^{*}+C^{*}}=\frac{\delta}{\gamma^{\prime}-\gamma}
$$

indicating that it can be minimised either by reducing conversion rate $\delta$ or by increasing the curing rate $\gamma^{\prime}$ of infected by resistant carrier as compared to its counterpart $\gamma$ for an ordinary carrier. However, at both $\delta$ and $\gamma^{\prime}$ finite, $f^{*}$ is always non-zero.

The SICS model formulated in Eq. (6) has in total four different characteristic rates: $\beta, \gamma, \gamma^{\prime}$ and $\delta$. However, the appearance of the solution (11) indicates the presence of combination such as $\gamma / \beta, \gamma^{\prime}-\gamma$, etc. that hints to the possibility of bringing down the number of independent parameters. Indeed, by introducing the following reduced parameters:

$$
\eta=\frac{\gamma+\delta}{\beta} \text { and } \chi=\frac{\delta}{\gamma^{\prime}-\gamma}
$$

the solution for a stationary state of a non-trivial fixed point (11) can be rewritten in much more compact form:

$$
\left\{\begin{aligned}
S^{*} & =\eta \\
I^{*} & =(1-\eta)(1-\chi), \\
C^{*} & =(1-\eta) \chi \\
f^{*} & =\chi
\end{aligned}\right.
$$

The meaning of the reduced parameters $\eta$ and $\chi$ can be easily established. $\eta$ can be written as $[\beta /(\gamma+\delta)]^{-1}$ and is, therefore, a reciprocal of the infecting strength of ordinary carrier, with respect to both curing and conversion. Reduced parameter $\chi$ has a meaning of a conversion strength with respect to the relative effectiveness of their curing, $\gamma^{\prime}-\gamma$. It is easy to see from both Eqs. (12) and (14) that it provides the relative fraction of resistant strain $f^{*}=\chi$ in a fixed point.

Reduced parameters are bound due to the obvious conditions: $S^{*}, I^{*}, C^{*} \in[0 ; 1]$. The first equation in Eqs. (14) yields $\eta \in[0 ; 1]$ straightaway. Then $(1-\eta) \in[0 ; 1]$ also holds. Conditions $I^{*}, C^{*} \in[0 ; 1]$ can be satisfied only if $\chi \in[0 ; 1]$, as follows from the second and third equations in Eqs. (14). Therefore:

$$
\eta \in[0 ; 1], \quad \chi \in[0 ; 1]
$$

The case $0<\eta<1$ and $0<\chi<1$ represents a non-trivial fixed point, whereas the boundary cases of 0 and 1 reproduce special fixed points. Namely, at $\eta=1$ one obtaines a trivial disease free fixed point $S^{*}=1, I^{*}=C^{*}=0$, whereas at $\chi=1$ one has $\delta=\gamma^{\prime}-\gamma \Rightarrow \eta=\gamma^{\prime} / \beta$ and, therefore, the full 
conversion fixed point $S^{*}=\gamma^{\prime} / \beta, I^{*}=0, C^{*}=1-\gamma^{\prime} / \beta$ is reproduced. Both these special fixed points are discussed above and are obtained at $\chi>0 \Rightarrow \delta>0$.

The case $\delta=0$ with no conversion is even more trivial, as now the model reduces itself to the SIS model: $\eta=\gamma / \beta$ and $S^{*}=\gamma / \beta, I^{*}=1-\gamma / \beta, C^{*}=0$. Finally, the case $\eta=0$ implies both $\gamma$ and $\delta$ to turn into zero and, therefore, $\chi$ also turns to zero. In this case no conversion and no curing takes place or the ordinary infection and it overtakes the population leading to the fixed point $I^{*}=1, \quad S^{*}=C^{*}=0$.

Due to reduction of the number of independent parameters to two, $\eta, \chi$, all the cases discussed above can be visualised easily on the $3 D$ plot, shown in Fig. 2. One, indeed, see clearly that at each particular value of $\chi$, reduced parameter $\eta$ affects the number of infected individuals $I^{*}$ and $C^{*}$, according to its meaning as the reciprocal infecting strength. On the other hand, at each $\eta$, the ratios of $I^{*}$ and $C^{*}$ follow the value of the parameter $\chi$, in accordance with Eqs. (14). It is clear from Fig. 2 that, to reduce the population of the most dangerous, resistant, strain one has two options: (i) to minimize conversion rate $\delta$ (i.e. to stay within the small $\chi$ region), or, if this is somehow problematic, to increase the value of $\eta$, which implies higher values of curing rate $\gamma$ and lower values of infecting rate $\beta$. Despite the fact that such

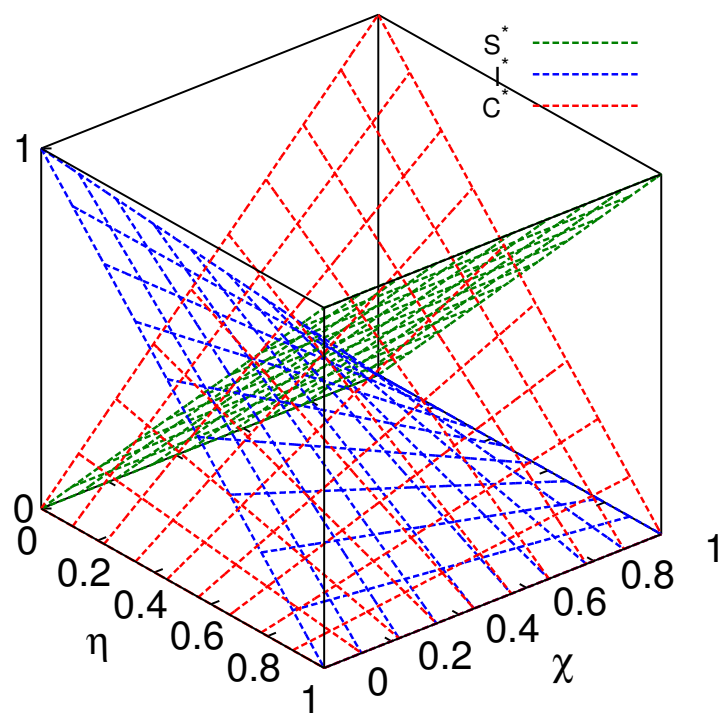

Fig. 2. 3D plot visualisation of the fixed points of the $S I C S$ epidemiology model in reduced parameter space $\eta, \chi$. result is qualitatively obvious from the beginning, both Eqs. (14) and Fig. 2 provide useful estimates for the quantitative evaluation of the effects related to each of these rates.

To conclude, the analysis of the fixed points of a simple model SICS for the disease with both ordinary and resistant carriers, performed here, provides a good starting point for the further inversigation of this particular model and for its future generalisation targeted on particular diseases (e.g. tuberculosis). In particular, one may extend this study to the analysis of stability of its solutions, to considering the case with unequal infecting rate for the ordinary and resistant carriers, as well as to the dynamics and spatial patterning of individuals if the model is formulated on particular graph [11-14]. This is planned for the future studies.

[1] Schwaber M. J., Navon-Venezia S., Kaye K. S., Ben-Ami R., Schwartz D., Carmeli Y. Clinical and Economic Impact of Bacteremia with Extended-Spectrum-Lactamase-Producing Enterobacteriaceae, Antimicrobial Agents and Chemotherapy. 50, n. 4, 1257-1262 (2006).

[2] Zapalac J. S., Billings K. R., Schwade N. D., Roland P. S. Suppurative Complications of Acute Otitis Media in the Era of Antibiotic Resistance. Archives of Otolaryngology-Head \& Neck Surgery, 128, n. 6, 660-663 (2002).

[3] Roberts R. R., Hota B., Ahmad I., ScottR. D. I., Foster S. D., Abbasi F., Schabowski S., Kampe L. M., Ciavarella G. G., Supino M., Naples J., Cordell R., Levy S. B., Weinstein R. A. Hospital and Societal Costs of Antimicrobial-Resistant Infections in a Chicago Teaching Hospital: Implications for Antibiotic Stewardship. Clinical Infectious Diseases. 49, n. 8, 1175-1184 (2009).

[4] Feshchenko Y., Dzyublik A., Pertseva T., Bratus E., Dzyublik Y., Gladka G., Morrissey I., Torumkuney D. Results from the Survey of Antibiotic Resistance (SOAR) 2011-13 in Ukraine. Journal of Antimicrobial Chemotherapy. 71, n. suppl1, i63-i69 (2016). 
[5] Cohen T., Dye C., Colijn C., Williams B., Murray M. Mathematical models of the epidemiology and control of drug-resistant TB. Expert Review of Respiratory Medicine. 3, n. 1, 67-79 (2009).

[6] Nieuwhof G., Conington J., Bishop S.C. A genetic epidemiological model to describe resistance to an endemic bacterial disease in livestock: application to footrot in sheep. Genetics Selection Evolution. 41, n. 1, 19 (2009).

[7] Zwerling A., Shrestha S., Dowdy D. W. Mathematical Modelling and Tuberculosis: Advances in Diagnostics and Novel Therapies. Advances in Medicine. 2015, 1-10 (2015).

[8] Fofana M. O., Shrestha S., Knight G. M., Cohen T., White R. G., Cobelens F., Dowdy D. W. A Multistrain Mathematical Model To Investigate the Role of Pyrazinamide in the Emergence of Extensively DrugResistant Tuberculosis. Antimicrobial Agents and Chemotherapy. 61, n. 3, e00498-16 (2016).

[9] Spicknall I. H., Foxman B., Marrs C. F., Eisenberg J. N. S. A Modeling Framework for the Evolution and Spread of Antibiotic Resistance: Literature Review and Model Categorization. American Journal of Epidemiology. 178, n. 4, 508-520 (2013).

[10] Feng Z. Applications of Epidemiological Models to Public Health Policymaking: The Role of Heterogeneity in Model Predictions. World Scientific Publishing Company (2014).

[11] Ilnytskyi J., Holovatch Y., Kozitsky Y., Ilnytskyi H. Computer simulations of a stochastic model for the non-immune disease spread. Bulletin of the National University "Lviv Polytechnic", 800, 176-184 (2014).

[12] Ilnytskyi J., Haiduchok O., Ilnytskyi H. Modelling of diaseses dissemination with multi-resistant pathogens. Computer technologies of Printing. 34, n. 2, 72-79 (2015), (in Ukrainian).

[13] Ilnytskyi H., Ilnytskyi J. Modelling of dynamics and clusterisation for the spread of the diseases with multidrug resistant carriers. Scientifically Capacitant Technologies. 28, n. 4, 296-3009 (2015), (in Ukrainian).

[14] Ilnytskyi J., Kozitsky Y., Ilnytskyi H., Haiduchok O. Stationary states and spatial patterning in anSISepidemiology model with implicit mobility. Physica A: Statistical Mechanics and its Applications. 461, $36-45$ (2016).

\title{
Проста епідеміологічна модель для неімунного захворювання із звичайними та резистентними збудниками
}

\author{
Ільницький $\Gamma{ }^{1}$, Ільницький $Я .^{2,3}$ \\ 1 Лъвівсъкий начіоналъний медичний університет ім. Данила Галицъкого \\ вул. Пекарсъка, 69, 79000, Лъвів, Україна \\ ${ }^{2}$ Інститут фізики конденсованих систем НАН України \\ вул. Свенціцького, 1, 79011, Львів, Україна \\ ${ }^{3}$ Начіональний університет "Львівсъка політехніка" \\ вул. С. Бандери, 12, 79013, Львів, Україна
}

\begin{abstract}
Запропоновано модель неімунного захворювання, яке переноситься як звичайним, так i резистентним збудниками. Ефективність поширення інфекції $\beta$ вважається однаковою для обох типів збудників, тоді як ефективності лікування $\gamma$ та $\gamma^{\prime}$ відповідно інфікованих звичайним та резистентним збудником відрізняється. Конверсія звичайного збудника у резистентний відбувається із ефективністю $\delta$. Проаналізовано стаціонарні стани моделі та здійснено переформулювання фіксованих точок у термінах двох параметрів, що є комбінацією початкових чотирьох ефективностей. Здійснено оцінку нижньої та верхньої меж цих параметрів та побудовано тривимірний графік фіксованих точок.
\end{abstract}

Ключові слова: епідеміологія, резистентні збудники.

2000 MSC: 92C60, 92D 30

УДК: 004.942:[616.9-022-021484:616-036.22] 